\section{The diagnosis of myocardial infarction in the first 16 hours after the onset of chest pain by measurement of $\log$ CK slope}

\section{Sir,}

Despite considerable research, the clinician remains limited by the lack of an investigation which is able to rapidly and reliably answer the question, 'is this patient's acute chest pain due to myocardial infarction (MI), or not?' Collinson et al.,' however, recently reported a study of 65 coronary care unit (CCU) patients, demonstrating that determination of the rate of rise of the logarithmic value of serum creatine kinase $(\mathrm{CK})$, measured over the first 12 hours of admission to the CCU, is able to accurately confirm or refute the clinical suspicion of MI.

I have studied this parameter prospectively in 16 patients ( 10 males, mean age 42 years, range 29-71) with a typical story of MI and supportive electrocardiographic (ECG) changes, provided they were admitted to the CCU within 4 hours of the onset of pain and had not received any intra-muscular injections. CK was measured, by standard laboratory methods, 4-hourly for $\mathbf{4 8}$ hours after the onset of pain. Serial ECGs and a "cardiac enzyme series' were assessed routinely.

MI, as judged by the evolution of typical ECG and cardiac enzyme changes, was confirmed in all patients; 8 patients' ECGs developed Q-waves (QMIs). Three patients received thrombolytic agents, none required DC cardioversion, and there were no reinfarctions or deaths.

The $C K$ values at 4, 8, 12 and 16 hours after the onset of pain were transformed logarithmically. The rate of rise of $\log$ CK (" $\log$ CK slope") was then calculated over 5 different time-periods: 4-8, 8-12, 12-16, 4-12 and 4-16 hours. The results are shown in Table I. The most relevant value is the minimum of 0.0151 , seen in the 4-8 hour period of a non-QMI patient. Excluding the 12-16 hour period, when the slopes flattened as peak values were approached, statistical analysis shows that $\log$ CK slopes $C$ of QMIs are significantly greater than those of non- $\vec{F}$ QMIs, and that $\log$ CK slopes are significantly correlated $\stackrel{\mathscr{P}}{\stackrel{+}{\mathscr{S}}}$ with the eventual peak CK value (see Table I).

The results are remarkably similar to the 34 of Collinson and colleagues' $65 \mathrm{CCU}$ patients who were eventually $\frac{\bar{\sigma}}{\sigma}$ proven to have had an MI. My study lacks a control $\widehat{\mathbb{D}}$ group of patients, subsequently shown not to have had an MI, and can therefore only support, rather than confirm is their findings. Their most important result was the $\overrightarrow{0}$ discriminant value of 0.015 , below which, MI can be excluded as the cause of acute chest pain. This is in accord $\vec{\omega}$ with the minimum value in my study $(0.0151$, see above). Collinson et al. calculated the log CK slope from four $\mathrm{CK}$ 응 levels, measured over the first 12 hours of admission. My 3 . data suggest that meaningful log CK slope values can be $\sigma$ calculated more rapidly from just two CK levels, measured only 4 hours apart in the period 4-16 hours $\infty$ after the onset of chest pain. Log CK slopes may also be of $\stackrel{\mathscr{\omega}}{\omega}$ prognostic value by prediction of infarct size ${ }^{2}$ and charac- $\omega_{\vec{N}}$ ter. ${ }^{3}$ As thrombolysis affects $\mathrm{CK}$ release kinetics, ${ }^{4}$ this will have to be taken into account in further studies.

$$
\begin{array}{r}
\text { P.J. Mullen, } \\
\text { Royal Air Force Hospital, } \\
\text { Wegberg, BFP0 } 40 ; \\
\text { Present addres, } \\
\text { University Department of Medicing } \\
\text { P.O. Box } 14 \\
\text { Liverpool L69 } 3 B
\end{array}
$$

\section{References}

1. Collinson, P.O., Ramhamadany, E.M., Rosalki, S.B. et al.

\begin{tabular}{|c|c|c|c|c|c|}
\hline & \multicolumn{5}{|c|}{ Time-period (hours after onset of pain) } \\
\hline & $4-8$ & $8-12$ & $12-16$ & $4-12$ & $4-16$ \\
\hline $\begin{array}{l}\text { QMI } \\
\text { median } \\
\text { range }\end{array}$ & $\begin{array}{c}0.1360 \\
0.0783-0.2034\end{array}$ & $\begin{array}{c}0.0894 \\
0.0692-0.1298\end{array}$ & $\begin{array}{c}0.0573 \\
0.0384-0.0896\end{array}$ & $\begin{array}{c}0.1168 \\
0.0787-0.1542\end{array}$ & $\begin{array}{c}0.0939 \\
0.0789-0.1173\end{array}$ \\
\hline $\begin{array}{l}\text { Non-QMI } \\
\text { median } \\
\text { range }\end{array}$ & $\begin{array}{c}0.0520 \\
0.0151-0.1098\end{array}$ & $\begin{array}{c}0.0625 \\
0.0451-0.0890\end{array}$ & $\begin{array}{c}0.0479 \\
0.0212-0.0701\end{array}$ & $\begin{array}{c}0.0615 \\
0.0345-0.0994\end{array}$ & $\begin{array}{c}0.0568 \\
0.0394-0.0734\end{array}$ \\
\hline $\begin{array}{l}\mathrm{Q} v s \text { non-QMI } \\
P \text { value* }\end{array}$ & $<0.001$ & 0.011 & 0.094 & $<0.001$ & $<0.001$ \\
\hline $\begin{array}{l}\text { All MIs } \\
\text { (correlation with peak CK) } \\
\text { r value** } \\
P \text { value }\end{array}$ & $\begin{array}{c}0.88 \\
<0.0001\end{array}$ & $\begin{array}{l}0.67 \\
0.005\end{array}$ & $\begin{array}{l}0.26 \\
0.334\end{array}$ & $\begin{array}{l}0.87 \\
<0.001\end{array}$ & $\begin{array}{c}0.94 \\
<0.0001\end{array}$ \\
\hline
\end{tabular}
Diagnosis of acute myocardial infarction from sequential enzyme measurements obtained within 12 hours of admission to hospital. J Clin Pathol 1989, 42: 1126-1131.

Table I Log CK slope values of patients with QMI $(n=8)$ and non-QMI $(n=8)$ measured over 5 different time-periods in the first 16 hours after the onset of chest pain, showing statistical comparison of the 2 groups and the correlation of $\log \mathrm{CK}$ slope values with eventual peak $\mathrm{CK}$ value 
2. Hackel, D.B., Reimer, K.A., Ideker, R.E. et al. Comparison of enzymatic and anatomic estimates of myocardial infarct size in man. Circulation 1984, 70: 824-835.

3. Ogawa, H., Hiramori, K., Haze, K. et al. Comparison of clinical features of non- $Q$ wave and $Q$ wave myocardial infarction. Am Heart J 1986, 111: 513-518.

4. Wei, J.Y., Markis, J.E., Malagold, M. \& Grossman, W. Time course of serum cardiac enzymes after intracoronary thrombolytic therapy. Arch Intern Med 1985, 145: 1596-1600.

\section{Mediastinal germ cell tumour and myelodysplastic syndrome}

Sir,

Nichols et al. ${ }^{1}$ have recently described 16 cases of haematological neoplasia associated with non-seminomatous mediastinal germ cell tumours and suggest that these neoplasms may arise from a common progenitor cell.

We wish to report a 20 year old man with an enormous primary mediastinal germ cell tumour with histological evidence of yolk-sac elements in combination with teratoma, and high alpha-fetoprotein (AFP) serum levels $(2130 \mathrm{ng} / \mathrm{ml})$. He was treated with six courses sequentially of combinations of cisplatin, etoposide, ifosfamide and bleomycin with a partial response as measured by thoracic scan and the reduction of AFP levels to $190 \mathrm{ng} / \mathrm{ml}$.

During the chemotherapy treatment, the patient developed persistent pancytopenia and a severe myelodysplastic syndrome with abnormal megakaryocytes in two bone marrow biopsies. The cytogenetic analysis demonstrated three abnormal clones: trisomy 1 with an extra marker chromosome, a second clone with, added to the first, a trisomy 18 and a third clone with an extra 8 chromosome. The karyotype yielded $48, \mathrm{XY},+1,+\operatorname{mar} / 49, \mathrm{XY}$, $+1,+18,+\operatorname{mar} / 50, \mathrm{XY},+1,+8,+18,+\operatorname{mar}$.

In the patients who develop a chemotherapy or radiotherapy related leukaemia or myelodysplastic syndrome, the karyotype usually shows a hypodiploid modal number and abnormalities in chromosomes 3, 5, 7 and $17 .^{2}$ However, in this patient's karyotype the deletions and monosomies often found in people with therapy related haematological neoplasms were not present. On the other hand, trisomy 8 , frequently observed in myelodysplastic syndromes, ${ }^{3}$ was found.

We feel that this young man with non-seminomatous primary mediastinal germ cell tumour and severe myelodysplastic syndrome with cytogenic abnormalities beginning after chemotherapy treatment, is similar to those patients reported by Nichols et al. ${ }^{1}$

M. Serrano, J.L. Rodriguez-García,

T. Ferro, G. Fraile, J.G. Laraña ${ }^{2}$

Departments of Internal Medicine,

${ }^{\prime}$ Genetics and ${ }^{2}$ Haematology, Hospital Ramón y Cajal, Madrid, Spain.

\section{References}

1. Nichols, C.R., Roth, B.J., Heerema, Griep, J. \& Tricot, G. Hematologic neoplasia associated with primary mediastinal germ-cell tumors. $N$ Engl J Med 1990, 322: 1425-1429.

2. Groupe Francais de Cytogenetique Hematologique. Chromosome analysis of 63 cases of secondary non-lymphoid blood disorders: a cooperative study. Cancer Genet Cytogenet 1984, 12: 95-104.

3. Musilova, J. \& Michalova, K. Chromosome study of $\mathbf{8 5}$ patients with myelodysplastic syndrome. Cancer Genet Cytogenet 1988, 33: 39-50.

\section{Doxycycline-induced parotitis}

Sir,

Sialadenitis is an uncommon side effect of drugs and chemicals such as nifedipine, ${ }^{1,2}$ alpha-methyldopa, ${ }^{3}$ phenylbutazone, ${ }^{4}$ interferon alpha, ${ }^{5}$ H2 receptor antagonists, ${ }^{6}$ oxyphenbutazone, ${ }^{7}$ iodine compounds ${ }^{8}$ and nitrofurantoin. ${ }^{9}$ To our knowledge, no cases of doxycycline-induced sialadenitis have been described until now.

An 18 year old female developed serum sickness while receiving doxycycline for inflammatory acne. She had been taking doxycycline $200 \mathrm{mg} /$ day orally for 15 days when she voluntarily discontinued the treatment for 1 week. Forty eight hours after reintroducing this drug, she developed fever $\left(38.2^{\circ} \mathrm{C}\right)$, chills, generalized urticaria, hand and foot oedema, and arthralgia in both knees, ankles and wrists. She had not received any other medication during the previous 3 months. Physical examination also revealed bilateral cervical lymphadenopathy up to $2 \mathrm{~cm}$ in diameter. Seventy-two hours later, she developed bilateral painful parotid swelling. There was tenderness, reddening and an increased temperature of the skin over the glands. Simultaneously, a recrudescence of urticarial lesions was observed. Other studies showed mild leukocytosis $(12,700 / \mathrm{mm})$, elevated ESR (52 $\mathrm{mm}$ in the first hour), hypocomplementaemia $(\mathrm{C} 4,10 \mathrm{mg} / \mathrm{dl})$ and proteinuria $(1.6 \mathrm{~g} / \mathrm{l})$ and haematuria (33 red cells per high power field). Serum protein electrophoresis and serum immunoglobulins were within normal limits. Antinuclear antibodies and hepatitis B surface antigen were not detected in serum. She was treated with methylprednisolone $80 \mathrm{mg}$ daily intravenously and hydroxyzine $100 \mathrm{mg} /$ day orally. The parotitis resolved in 24 hours and the rest of the clinical manifestations in 5 days.

The mechanism of drug-induced sialadenitis remains unclear in most cases. Either oedema and spasm of smooth muscle in the salivary gland or a hypersensitivity reaction could be responsible. , $^{1,35-7,9}$ In the case reported here, the association between serum sickness and parotitis during doxycycline therapy points to an immunological pathogenesis.

Carmen Vidal Pan Arturo González Quintela' Departments of Allergy and 'Internal Medicine, Hospital Puerta de Hierro, c) San Martín de Porres 4, 28035 Madrid, Spain. 